\title{
Youth Physical Activity and Enjoyment during Semi-Structured versus Unstructured School Recess
}

\author{
Jessyka N. Larson, Timothy A. Brusseau, Benjamin Chase, Angela Heinemann, \\ James C. Hannon \\ Department of Exercise and Sport Science, University of Utah, Salt Lake City, UT, USA \\ Email: jessyka.larson@gmail.com, tim.brusseau@utah.edu, benjaminchase@mail.weber.edu, \\ angelamheinemann@gmail.com, james.hannon@hsc.utah.edu
}

Received 30 June 2014; revised 24 July 2014; accepted 4 August 2014

Copyright (C) 2014 by authors and Scientific Research Publishing Inc.

This work is licensed under the Creative Commons Attribution International License (CC BY). http://creativecommons.org/licenses/by/4.0/

(c) (7) Open Access

\begin{abstract}
Background: Physical activity throughout the school day may help reduce the risk of childhood obesity. Semi-structured recess is a unique approach to create more physical activity. Therefore, the purpose of this study was to compare the physical activity and enjoyment of urban school children during traditional unstructured recess and semi-structured recess. Method: Children from the Southwestern US $(\mathrm{N}=165)$ wore a $\mathrm{NL-1000}$ piezoelectric accelerometer during their 15-minute lunch recess. Children participated in both their traditional unstructured (no structure and no equipment) recess and semi-structured (organized games and equipment) recess. An enjoyment scale was completed after both types of recess formats. Results: During unstructured recess, children accumulated $1028 \pm 356$ steps and $4.59 \pm 2.2$ minutes of MVPA compared to $1156 \pm$ 434 steps and $5.44 \pm 2.76$ minutes of moderate to vigorous physical activity (MVPA) during semi-structured recess. Paired sample $t$-tests revealed that children took significantly more steps $(t=-4.98 ; p<0.001)$ and MVPA $(t=-5.940 ; p<0.001)$ during semi-structured recess. No significant differences were found for enjoyment $(p=0.847)$ between recesses. Conclusions: It is important for schools to consider creative, semi-structured recess opportunities to increase step counts and time in MVPA (while maintaining enjoyment) and reinforce recess as an important component of a comprehensive school physical activity program.
\end{abstract}

Keywords

Moderate-to-Vigorous Physical Activity (MVPA), Step Counts, Physical Education

\section{Introduction}

The prevalence of physical inactivity among school-aged children has contributed to the substantial rise in

How to cite this paper: Larson, J.N., Brusseau, T.A., Chase, B., Heinemann, A. and Hannon, J.C. (2014) Youth Physical Activity and Enjoyment during Semi-Structured versus Unstructured School Recess. Open Journal of Preventive Medicine, 4, 631-639. http://dx.doi.org/10.4236/ojpm.2014.48072 
overweight and obesity [1]. Obesity has increased in the US dramatically over the past ten years with approximately $31.8 \%$ of children classified as overweight or obese [2]. Many health risks are associated with overweight and obesity including cardiovascular disease, type II diabetes, hypertension, certain types of cancer, and risk of stroke [1]. The obesity epidemic is affecting children of all ages including young children and adolescents and when obesity occurs during adolescence, it tends to persist into adulthood [3].

Physical activity (PA) during childhood has shown to be effective in preventing health problems later in life [4]. To decrease the risk of overweight and obesity, it is recommended that children engage in moderate to vigorous physical activity (MVPA) for at least 60 minutes each day [5] or at least 12,000 steps/day [6]. Due to the accessibility of children, schools are an ideal setting for promoting PA [7]. Most children in the United States are in school for 30 - 35 hours per week. However, the opportunity for children to be physically active during school has decreased due to many factors including an increase in vehicle transportation to school, environmental factors, school policy, and reducing time children spend in physical education (PE) and at recess [8]. Although PE and recess are two opportunities for children to be physically active during the school day, many schools offer PE only 1 - 2 days per week which does not provide a sufficient amount of activity to meet the recommended 60 minutes of MVPA per day [9]. Therefore, school recess presents an additional opportunity for students to be involved in PA. When combined with regular PE, recess can help children get closer to the daily PA recommendations. Recess is defined as "regularly scheduled periods within the elementary school day for physical activity and play” [10]. It is a break children receive during the school day from cognitive tasks. Daily recess has been shown to play a significant role in increasing PA as well as increasing learning, productivity, concentration, and social development [11]. Research studies have found that lunchtime recess can contribute between $11 \%$ - $21 \%$ of daily step counts among children [12]-[14]. Other studies have found that recess can give children the opportunity to play, imagine, move, socialize, and has the potential to contribute up to $40 \%$ of a child's daily PA recommendations [15]. When children are allowed recess time, they benefit academically, cognitively, emotionally, physically, and socially [16]. Many studies have shown that classroom behavior is improved with recess as giving students a break from challenging mental tasks allows them to come back to class refocused and more on task [5] [9] [11] [17].

Although recess is an effective time to promote PA, some children do not use this time to be physically active [18]. Research has found that structured recess can be a novel approach to provide new PA choices at recess [19]. There are many benefits of structured recess including older elementary students benefiting from game instruction and encouragement, class inclusion, and improved behavior and attention in the classroom after recess [12]. A study by Howe et al. suggests that a more structured recess can increase PA when compared to unstructured recess [18]. Existing research also found that providing structured recess can increase children's PA [8] [20]. Research has shown that elementary school-aged children are more active when supervisors encourage PA and implement games [21]. Others perceive recess as a time where play should be unstructured and allowed for children to be creative and have their own personal time [16]. A closer examination of the effects of unstructured recess and semi-structured recess needs to be studied and evaluated. It is also important to examine the effect that unstructured recess and semi-structured recess have on enjoyment. Enjoyment may influence behavior and have an indirect effect on PA [22]. Providing children with different types of PA has been shown to increase participation and enjoyment [23].

Therefore, the purpose of this present study was to compare the PA (step counts; minutes spent in MVPA) accumulated during semi-structured recess and traditional unstructured recess and to examine PA enjoyment in 3 - 5 grade elementary school-aged children at an urban elementary school in the Southwest US. This age group was chosen because pre-adolescents are at high-risk obesity development [23]-[25]. A semi-structured recess intervention was chosen for this study because it creates structure for PA while allowing free play.

The current study will address the following research questions: 1) Does semi-structured recess increase children's step counts and MVPA? 2) Does grade or BMI influence step counts and MVPA during semi-structured recess? 3) Is student enjoyment affected by semi-structured recess?

\section{Methods}

\subsection{Participants}

The sample for this study consisted of 165 elementary school children $(n=89$ males $)$ in the Southwestern United States. Students were recruited via PE class while at school. Exclusion criteria included any existing injuries 
which prohibited a student from participating in recess activities. Students were $61 \%$ Hispanic, $15 \%$ Caucasian, 14\% Asian/Pacific Islander, 4\% African-American, 4\% two or more races, and 2\% American Indian. All 165 students completed the study during the spring of 2013. Children represented grades 3 through 5 ( $n=56$ third graders; $n=57$ fourth graders; $n=52$ fifth graders). Participants had an overall body mass index (BMI) mean of 19.03. Sixty-nine (41\%) children had BMI equal or above the $85^{\text {th }}$ percentile (overweight or obese) $(M=23.3$, $S D=1.66)$ and $96(59 \%)$ children had healthy BMI less than the $85^{\text {th }}$ percentile $(M=15.84, S D=3.73)$. The percentage of children at this elementary school who were eligible to receive free or reduced-price lunch was $87 \%$.

\subsection{Instrumentation}

\subsubsection{Accelerometers}

New Lifestyles NL-1000 accelerometers were used to assess number of steps taken and the number of minutes in MVPA by the participants. The NL-1000 has been previously validated in elementary aged children [26]. The NL-1000 is a piezoelectric accelerometer that measures step counts and time spent in MVPA. MVPA setting were set at 3 - 9 mets based on previous research with this age group [14] [27].

\subsubsection{Revised Physical Activity Enjoyment Scale (PACES)}

Children completed an enjoyment scale questionnaire that included questions about enjoyment level while being physically active at recess. The questions included stem: when I am physically active at recess 1 . I enjoy it; 2 . I feel bored; 3. I dislike it; 4. It's no fun at all; 5. It gives me energy; 6. It’s very fun; 7. My body feels good; 8. It's very exciting; 9. It frustrates me; 10. It's not at all interesting; 11. It gives me a strong feeling of success; 12. I feel as though I would rather be doing something else [28].

Students filled out the questionnaire during the unstructured week of recess and filled out the same questionnaire during the week of semi-structured recess. Enjoyment represents a key factor underlying the exercise motivation for children and adolescents to maintain positive engagement in PA and has been shown to be significantly correlated to youth being moderate to vigorously physically active [29].

\subsection{Recess Environment}

The school playground included a blacktop surface with five basketball hoops, two playground structures, a state and US map playground marking, three hop scotch playground markings, and a large grass area with two soccer goals for free play. The entire playground was available to students in grades 3 through 5 . Recess time was provided before or after lunch based on grade level. Third graders went to recess for 15 minutes before they went to lunch. Fourth and fifth graders went to lunch first and then to recess for 15 minutes. Each grade level went to recess at separate times. During recess, the estimated number of children on the playground at one time ranged from 50 - 60 students with two supervisors.

\subsection{Procedure}

University institutional review board (IRB) and school district/principal approval were obtained prior to conducting the study. Following administrative approval, parental consent and student assent was obtained and a short demographic sheet was completed.

Although research has shown that reactivity is not an issue [30], children participated in two weeks of using the accelerometers in PE class to get accustomed to wearing them and insuring the proper placement of the accelerometers. Each accelerometer was marked with a personalized code so that data could be connected with each participant's demographic data.

\subsubsection{Body Mass Index}

Height and weight for each participant were measured by two of the researchers during PE class using a digital scale and stadiometer. BMI and BMI percentiles were calculated on the Center for Disease Control and Prevention BMI-for-age growth chart [31]. Children's BMI percentile was coded into categories of healthy weight (5 ${ }^{\text {th }}$ percentile up to the $85^{\text {th }}$ percentile) and overweight or obese $\left(85^{\text {th }}\right.$ percentile or greater $)$ for analysis. 


\subsubsection{Unstructured Recess (4 School Days)}

For the purposes of this study, unstructured recess was defined as free play in which students' chose how they spent their time at lunch recess. Accelerometers were distributed to each child prior to them entering the playground area. The students were instructed to attach their accelerometer on their waistband over their right hip in line with the knee. Researchers were available to help those students who needed assistance getting their accelerometers on and to ensure the correct placement of the accelerometers. Participants were required to wear their accelerometers during the 15-minute lunch recess each day. While at recess, the participants were allowed to move about the playground as they chose in their traditional recess format which was unstructured free play with limited equipment. The students were supervised for safety purposes but were not given instruction on what activities to engage in. Accelerometers were collected at the end of the 15-minute recess period and step counts for each participant as well minutes of MVPA were recorded. After the 4 days of unstructured recess, students filled out a revised PACES questionnaire.

\subsubsection{Semi-Structured Recess (4 School Days)}

For the purpose of this study, semi-structured recess was defined as set activities, which were directed by supervisors. All semi-structured activities were demonstrated in PE class prior to the study. Every participant was encouraged to participate in a semi-structured activity. Accelerometers were distributed and attached the same way as the unstructured recess days. Recess supervisors included the PE teacher and recess aides. While at recess, participants were able to choose to engage in any one of five semi-structured activities provided which included:

Jump Rope. Participants were provided individual jump ropes to use in a designated area. They were encourages to perform jump rope tasks/games that they had learned in PE class.

Soccer. Participants were encouraged to play a two-ball soccer game that they learned during PE class. They had gone over the rules prior to playing the game at recess.

Basketball. Basketballs were provided for participants to use on the basketball court. They were encouraged to practice basketball skills/games that involved dribbling and shooting.

Tag Games. Participants were in a designated area and were encouraged to play different types of tag games such as Magic Tag, Freeze Tag, Ball Tag, etc.

Walking. There was a designated area on the grass field where participants could walk during the 15-minute recess period.

Students were allowed to move from station to station during the recess period. After the four days of semistructured recess, students filled out a revised PACES questionnaire and accelerometers were collected and recorded identical to the unstructured recess phase.

\subsection{Data Analysis}

Accelerometer data were examined to determine the mean and standard deviation for step counts and minutes spent in MVPA during unstructured and semi-structured recess. Questionnaire data was used to determine PA enjoyment during unstructured and semi-structured recess. Analyses were conducted using IBM Statistics SPSS 21.0 software. Descriptive analyses included means and standard deviations of recess PA as measured by step counts and time spent in MVPA as measured by active minutes according to sex, grade level, and BMI category. Paired sample t-tests were conducted to determine whether differences existed in children's step counts and minutes spent in MVPA as well as enjoyment during recess among the different weeks. A 2 (Gender) $\times 2$ (BMI category) $\times 3$ (Grade level) ANOVA was used to examine differences in PA, MVPA, and Enjoyment.

\section{Results}

\subsection{Step Counts}

Results from this study exhibited an increase in step counts at lunch recess during the semi-structured intervention. Figure 1 represents the difference in steps taken during semi-structured recess compared to unstructured recess by sex. A paired t-test revealed a significant difference between unstructured and semi-structured PA during lunchtime recess $(t=-4.981, p<0.00, r=0.67)$. A factorial ANOVA reported grade having an effect on step counts $F(2,162)=43.427(p<0.001)$. BMI did not have a significant effect on step counts $F(1,163)=$ 


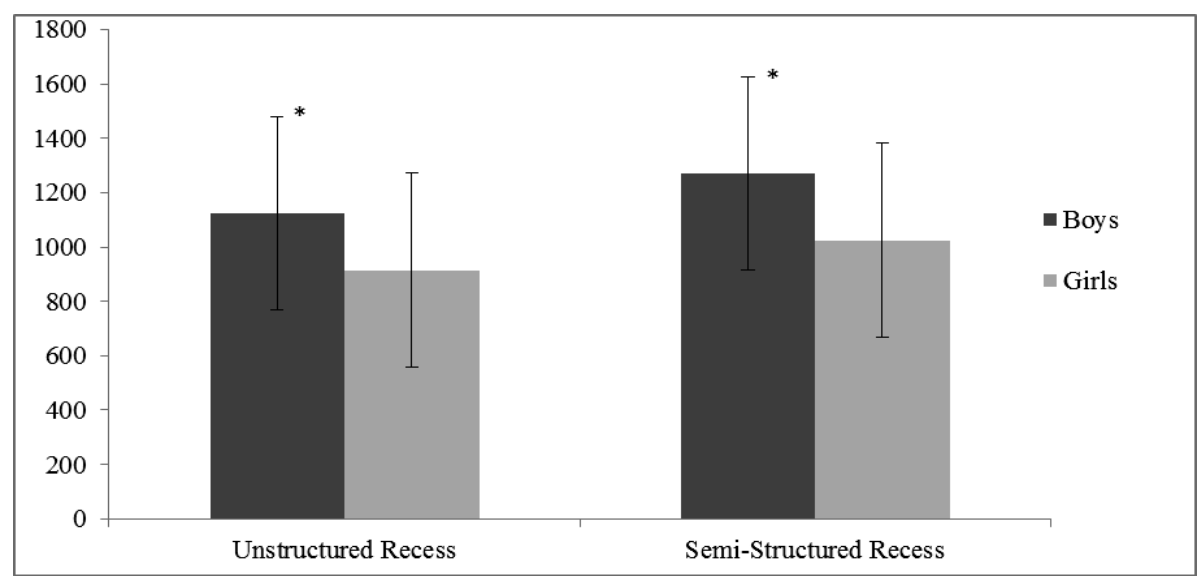

Figure 1. Mean differences representing step counts for boys and girls during unstructured and semi-structured recess. ${ }^{*}$ Significant difference $(p<0.05)$.

$2.737(p=0.10)$.

Both boys and girls significantly $(p<0.05)$ increased their PA during the intervention week. A significant difference $(p<0.001)$ in steps taken was found during unstructured recess among boys $(1125.23 \pm 346.03)$ and girls $(915.191 \pm 337.35)$. A significant difference, $F(1,163)=14.028(p<0.05)$ was also found during semistructured recess among boys (1269.44 \pm 445.82$)$ and girls (1025.03 \pm 382.37$)$.

\subsection{MVPA}

Results showed a significant difference $(t=-5.94, p<0.00, r=0.745)$ in minutes students $(\mathrm{n}=165)$ spent in MVPA between unstructured recess and semi-structured recess. Figure 2 represents the time spent in MVPA during unstructured and semi-structured recess by sex.

Boys spent more time in MVPA than girls throughout the study, $F(1,163)=13.718(p<0.001)$. During the week of unstructured recess, boys spent a mean of 5.19 minutes in MVPA (SD $=2.17$ ) and girls spent a mean of 3.88 minutes in MVPA (SD = 2.04). Both boys and girls significantly increased their activity time during the week of semi-structured recess $(p<0.001)$.

\subsection{Grade and BMI Differences}

Overall step count means, minutes in MVPA, and standard deviations by grade level are reported in Table 1. Fourth and fifth graders were significantly more physically active than third graders throughout the intervention $(p<0.001)$. There was no significant difference between fourth and fifth graders' PA. Fourth graders were the most active group during unstructured recess with a mean of 1188.45 steps and fifth graders were the most active group during semi-structured recess with a mean of 1352.68 steps. Fourth and fifth graders spent significantly more time in MVPA than third graders throughout the intervention $F(2,162)=20.17(p<0.001)$. In total, fourth graders spent the most time in MVPA averaging 6.38 minutes compared to third graders (3.73 minutes) and fifth graders (6.26 minutes). Results revealed that BMI did not significantly affect children's activity level during recess.

\subsection{Enjoyment Levels during Unstructured and Semi-Structured Recess}

A paired t-test and factorial ANOVA were used to analyze children's enjoyment during unstructured recess compared to semi-structured recess. Results showed that there were no significant differences $(p=0.847)$ between unstructured recess enjoyment and semi-structured recess enjoyment. Results also showed that gender, $F$ $(1,163)=0.000(t=-0.002, p=0.999)$, grade level, $F(2,162)=1.113(p=0.331)$, and BMI, $F=2.527(t=$ $-1.59, p=0.114$ ) did not create significant differences on enjoyment during recess.

\section{Discussion}

The purpose of this study was to compare the PA (step counts and MVPA) and enjoyment during semi-struc- 


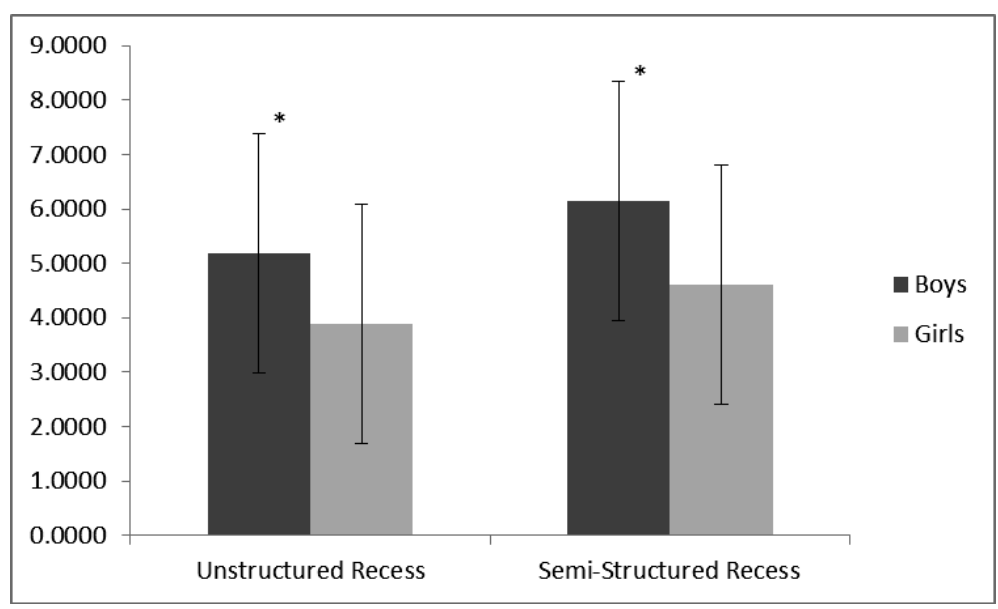

Figure 2. Mean differences in MVPA by sex during unstructured and semistructured recess. ${ }^{*}$ Significant difference $(p<0.05)$.

Table 1. Descriptive statistics for overall (2 weeks combined) and each week of physical activity and minutes in MVPA by elementary level and BMI.

\begin{tabular}{ccccc}
\hline & Unstructured Recess & Semi-Structured Recess & Unstructured Recess & Semi-Structured Recess \\
\hline & step counts \pm SD & step counts \pm SD & minutes in MVPA \pm SD & minutes in MVPA \pm SD \\
\hline $\begin{array}{c}\text { Overall } \\
\text { Elementary Level }\end{array}$ & $1028.48 \pm 356.82$ & $1156.87 \pm 434.10$ & $4.59 \pm 2.20$ & $5.44 \pm 2.76$ \\
3rd Grade $(\mathrm{n}=56)$ & $800.99 \pm 277.81$ & $828.42 \pm 286.96$ & $3.48 \pm 1.65$ & $3.73 \pm 1.65$ \\
4th Grade $(\mathrm{n}=57)$ & $1188.45 \pm 359.83$ & $1300.91 \pm 429.75$ & $5.43 \pm 2.49$ & $6.38 \pm 3.16$ \\
5th Grade $(\mathrm{n}=52)$ & $1098.13 \pm 306.03$ & $1352.68 \pm 365.58$ & $4.86 \pm 2.20$ & $6.28 \pm 2.40$ \\
BMI & & & & $5.24 \pm 2.68$ \\
HW (n = 96) & $1021.55 \pm 358.95$ & $1109.70 \pm 430.80$ & $4.61 \pm 2.17$ & $5.71 \pm 2.89$ \\
OW/Obese $(\mathrm{n}=$ 69) & $1037.20 \pm 358.88$ & $1222.76 \pm 435.73$ & $4.56 \pm 2.28$ & \\
\hline
\end{tabular}

Note: $\mathrm{HW}=$ healthy weight, $\mathrm{OW}=$ overweight; $4^{\text {th }}$ and $5^{\text {th }}$ graders were significantly more active than $3^{\text {rd }}$ graders $(p<0.05)$; no differences by BMI groups.

tured recess vs. unstructured recess in 3 - 5 grade children at an urban elementary school in the Southwest United States. The results revealed that semi-structured recess produced significantly more steps and MVPA compared to unstructured recess. These results are consistent with other research indicating the benefits of structured recess on PA [32].

This result is important for a few reasons. First, aside from PE, recess is a time that children have the opportunity to be physically active and accumulate some of the needed activity to meet the daily recommendations. Second, the equipment and stations used in the intervention were simple to use and inexpensive, and the stations were easy to conduct.

Previous research has reported that children average 1071 [13], 1090 [33] or 1250 [14] steps in a 15-minute recess. Children in this current study averaged less steps when compared to previous research during unstructured recess $(1028.48 \pm 356.82)$, however, step counts were more in line with previous research during semistructured recess $(1156.86 \pm 434.10)$. Although some studies have reported that children only spend $20 \%$ of school playtime in MVPA [34], our study reported children spending an average of $34 \%$ of unstructured recess time and $36 \%$ of semi-structured recess time in MVPA. These percentages however are still not meeting the recommend 40\% of recess time spent in MVPA for children [15].

Differences between boys and girls during semi-structured recess revealed that boys were more active than girls. Boys were also more active than girls during the week of unstructured recess. These findings are consistent with other research indicating that boys are more active than girls while at recess [12] [13] [15] [19]. This present study indicates that while boys are more active overall during recess, both boys and girls experienced significant increases in their step counts and MVPA during the intervention. Providing semi-structured activities 
that are appealing to both boys and girls may also play a role in levels of PA among each sex during recess.

Fourth graders were the most active during the 15-minute recess period when compared to third and fifth graders. A significant difference was found among fourth grade and third grade PA. These results are consistent with other research comparing younger elementary grades on older elementary grades [19]. This difference may be due to third graders going to recess for 15 minutes before they went to lunch as opposed to after. Fourth and fifth graders went to recess after lunch and may have had additional energy to play. Enjoyment did not significantly change during semi-structured recess for any of the grades. BMI and gender also did not have a significant effect on enjoyment during recess. Often enjoyment leads to activity [21] therefore, it is important to note that adding some structure to recess and increasing PA did not hinder enjoyment. This is important to recognize because enjoyment during PA often leads to increased levels of MVPA among children [26].

Limitations of the present study should be mentioned. First, this was a repeated measures study and so each child served as their own control. Studies in the future should incorporate a true control school along with an intervention school(s). Second, the outside temperature during the intervention was below normal for the time of year in the area. The average temperature was $42.63^{\circ} \mathrm{F}$ compared to a typical average of $61^{\circ} \mathrm{F}$ in the area during the time of year the intervention was conducted. This may have affected the amount of PA that students participated in.

The study completed suggests that semi-structured recess represents a feasible and viable intervention for schools to implement for promoting PA. Our findings indicate that a semi-structured recess environment may create more PA among children while at school. Implementing semi-structured recess is an inexpensive, simple way to increase children's PA for schools during lunch recess so they can accumulate more minutes of daily recommended MVPA without causing a negative effect on enjoyment. Further research is necessary to determine the effectiveness of semi-structured recess on PA, MVPA, and recess enjoyment on children.

\section{Acknowledgements}

This research was supported by Tacara Lovings, Jessica Wilson, Trei Chae Holmes, and Abby Lee who assisted in data collection.

\section{References}

[1] Strong, W.B., Malina, R.M., Blmkie, C.J.R., et al. (2005) Evidence Based Physical Activity for School-Aged Youth. Journal of Pediatrics, 146, 732-737. http://dx.doi.org/10.1016/j.jpeds.2005.01.055

[2] Ogden, C.L., Carroll, M.D., Kit, B.K. and Flegal, K.M. (2012) Prevalence of Obesity and Trends in Body Mass Index among US Children and Adolescents, 1999-2010. Journal of the American Medical Association, 307, 483-490. http://dx.doi.org/10.1016/j.jpeds.2005.01.055

[3] Crombie, A.P., Ilich, J.Z., Dutton, G.R., Panton, L.B. and Abood, D.A. (2009) The Freshman Weight Gain Phenomenon Revisited. Nutrition Reviews, 67, 83-94. http://dx.doi.org/10.1111/j.1753-4887.2008.00143.X

[4] Gutin, B., Barbeau, P., Owens, S., et al. (2002) Effects of Exercise Intensity on Cardiovascular Fitness, Total Body Composition, and Visceral Adiposity of Obese Adolescents. American Journal of Clinical Nutrition, 75, 818-826.

[5] Power, T.G., Ullrich-French, S., Steele, M.M., Daratha, K.B. and Bindler, R.C. (2011) Obesity, Cardiovascular Fitness, and Physically Active Adolescents' Motivations for Activity: A Self-Determination Theory Approach. Psychology of Sport and Exercise, 12, 593-598. http://dx.doi.org/10.1016/j.psychsport.2011.07.002

[6] Colley, R.C., Janssen, I. and Tremblay, M.S. (2012) Daily Step Target Adherence to Physical Activity Guidelines in Children. Medicine Science in Sports Exercise, 44, 977-982. http://dx.doi.org/10.1249/MSS.0b013e31823f23b1

[7] Verstraete, S.J.M., Cardon, G.M., De Clercq, D.L.R. and De Bourdeaudhuij, I.M.M. (2006) Increasing Children’s Physical Activity Levels during Recess Periods in Elementary Schools: The Effects of Providing Game Equipment. European Journal of Public Health, 16, 415-419. http://dx.doi.org/10.1093/eurpub/ckl008

[8] Dollman, J., Norton, K. and Norton, L. (2005) Evidence for Secular Trends in Children's Physical Activity Behavior. British Journal of Sports Medicine, 39, 892-897. http://dx.doi.org/10.1136/bjsm.2004.016675

[9] Huberty, J.L., Siahpush, M., Beighle, A., Fuhrmeister, E., Silva, P. and Welk, G. (2011) Ready for Recess: A Pilot Study to Increase Physical Activity in Elementary School Children. Journal of School Health, 81, 251-257. http://dx.doi.org/10.1111/j.1746-1561.2011.00591.x

[10] Murray, R., Ramstetter, C., Devore, C., et al. (2013) The Crucial Role of Recess in School. Pediatrics, 131, 183-188. http://dx.doi.org/10.1542/peds.2012-2993 
[11] Center for Disease Control and Prevention. BMI Percentile Chart for Child and Teen English Version. http://www.cdc.gov/healthyweight/assessing/bmi/index.html

[12] Brusseau, T.A., Kulinna, P.H., Tudor-Locke, C. and Ferry, M. (2013) Daily Physical Activity Patterns of Children Living in an American Indian Community. Journal of Physical Activity and Health, 10, 48-53.

[13] Brusseau, T.A., Kulinna, P.H., Tudor-Locke, C., Ferry, M., Van Der Mars, H. and Darst, P.W. (2011) Pedometer-Determined Segmented Physical Activity Patterns of Fourth- and Fifth-Grade Children. Journal of Physical Activity and Health, 8, 279-286.

[14] Tudor-Locke, C., Lee, S.M., Morgan, C.F., Beighle, A. and Pangrazi, R.P. (2006) Children’s Pedometer-Determined Physical Activity during the Segmented School Day. Medicine \& Science in Sports \& Exercise, 38, 1732-1738. http://dx.doi.org/10.1249/01.mss.0000230212.55119.98

[15] Ridgers, N.D., Stratton, G. and Fairclough, S.J. (2006) Physical Activity Levels of Children during School Playtime. Sports Medicine, 36, 359-371. http://dx.doi.org/10.2165/00007256-200636040-00005

[16] Ramstetter, C.L., Murray, R. and Gardner, A.S. (2010) The Crucial Role of Recess in Schools. Journal of School Health, 80, 517-526. http://dx.doi.org/10.1111/j.1746-1561.2010.00537.x

[17] Ginsburg, K.R. (2007) The Importance of Play in Promoting Healthy Child Development and Maintaining Strong Parent-Child Bonds. Pediatrics, 119, 182-191. http://dx.doi.org/10.1542/peds.2006-2697

[18] Howe, C.A., Freedson, P.S., Alhassan, S., Feldman, H.A. and Osganian, S.K. (2011) A Recess Intervention to Promote Moderate-to-Vigorous Physical Activity. Pediatric Obesity, 7, 82-88. http://dx.doi.org/10.1111/j.2047-6310.2011.00007.x

[19] Stellino, M.B., Sinclair, C.D., Partridge, J.A. and King, K.M. (2009) Differences in Children’s Recess Physical Activity: Recess Activity of the Week Intervention. Journal of School Health, 80, 436-444. http://dx.doi.org/10.1111/j.1746-1561.2010.00525.x

[20] Scruggs, P.W., Beveridge, S.K. and Watson, D.L. (2003) Increasing Children's School Time Physical Activity Using Structured Fitness Breaks. Pediatric Exercise Science, 15, 156-169.

[21] Connolly, P. and McKenzie, T.L. (1995) Effects of a Games Intervention on the Physical Activity Levels of Children at Recess. Research Quarterly for Exercise Sport, 66, 60-65.

[22] Dishman, R.K., Motl, R.W., Saunders, R., Felton, G., Ward, D.S., Dowda, M., et al. (2005) Enjoyment Mediates Effects of a School-Based Physical-Activity Intervention. Medicine and Science in Sports and Exercise, 37, 478-487. http://dx.doi.org/10.1249/01.MSS.0000155391.62733.A7

[23] Macphail, A., Gorley, T. and Kirk, D. (2003) Young People’s Socialization into Sport: A Case Study of an Athletics Club. Sport, Education and Society, 8, 251-267. http://dx.doi.org/10.1080/13573320309251

[24] Alberga, A.S., Sigal, R.J., Goldfield, G., Prud'Homme, D. and Kenny, G.P. (2012) Overweight and Obese Teenagers: Why Is Adolescence a Critical Period? Pediatric Obesity, 7, 261-273

[25] Wardle, J., Broderson, N.H., Cole, T.J., Jarvis, M.J. and Boniface, D.R. (2006) Development of Adiposity in Adolescence: Five Year Longitudinal Study of an Ethnically and Socioeconomically Diverse Sample of Young People in Britain. BMJ, 332, 1130-1135. http://dx.doi.org/10.1136/bmj.38807.594792.AE

[26] Hart, T.L., Brusseau, T.A., Kulinna, P.H., McClain, J.J. and Tudor-Locke, C. (2011) Evaluation of Low-Cost, Objective Instruments for Assessing Physical Activity in 10 - 11-Year-Old Children. Research Quarterly for Exercise and Sport, 82, 600-609. http://dx.doi.org/10.1080/02701367.2011.10599796

[27] McClain, J.J., Sisson, S.B., Washington, T.L., Craig, C.L. and Tudor-Locke, C. (2007) Comparison of Kenz Lifecorder EX and ActiGraph Accelerometers in 10-yr-Old Children. Medicine \& Science in Sports \& Exercise, 39, 630-638. http://dx.doi.org/10.1249/mss.0b013e3180313056

[28] Kendzierski, D. and DeCarlo, K. (1991) Physical Activity Enjoyment Scale: Two Validation Studies. Journal of Sport \& Exercise Psychology, 13, 50-64.

[29] Motl, R.W., Dishman, R.K., Saunders, R., Dowda, M., Felton, G. and Pate, R.R. (2001) Measuring Enjoyment of Physical Activity in Adolescent Girls. American Journal of Preventive Medicine, 21, 110-117. http://dx.doi.org/10.1016/S0749-3797(01)00326-9

[30] Prewitt, S.L., Hannon, J.C. and Brusseau, T.A. (2013) Children and Pedometers: A Study in Reactivity and Knowledge. International Journal of Exercise Science, 6, 230-235.

[31] Centers for Disease Control and Prevention (2000) Promoting Better Health for Young People through Physical Activity and Sports. http://www2.ed.gov/offices/OSDFS/physedapndc.pdf

[32] Mota, J., Silva, P., Santos, M.P., Ribeiro, J.C., Oliveira, J. and Duarte, J.A. (2005) Physical Activity and School Recess Time: Differences between the Sexes and the Relationship between Children's Playground Physical Activity and Habitual Physical Activity. Journal of Sports Sciences, 23, 269-275. http://dx.doi.org/10.1080/02640410410001730124 
[33] Beighle, A., Morgan, C.F., Masurier, G.L. and Pangrazi, R.P. (2006) Children’s Physical Activity during Recess and Outside of School. Journal of School Health, 76, 516-520. http://dx.doi.org/10.1111/j.1746-1561.2006.00151.x

[34] Stratton, G. and Leanord, J. (2002) The Effects of Playground Markings on the Energy Expenditure of 5- to 7-YearOld School Children. Pediatric Exercise Science, 14, 170-180. 
Scientific Research Publishing (SCIRP) is one of the largest Open Access journal publishers. It is currently publishing more than 200 open access, online, peer-reviewed journals covering a wide range of academic disciplines. SCIRP serves the worldwide academic communities and contributes to the progress and application of science with its publication.

Other selected journals from SCIRP are listed as below. Submit your manuscript to us via either submit@scirp.org or Online Submission Portal.
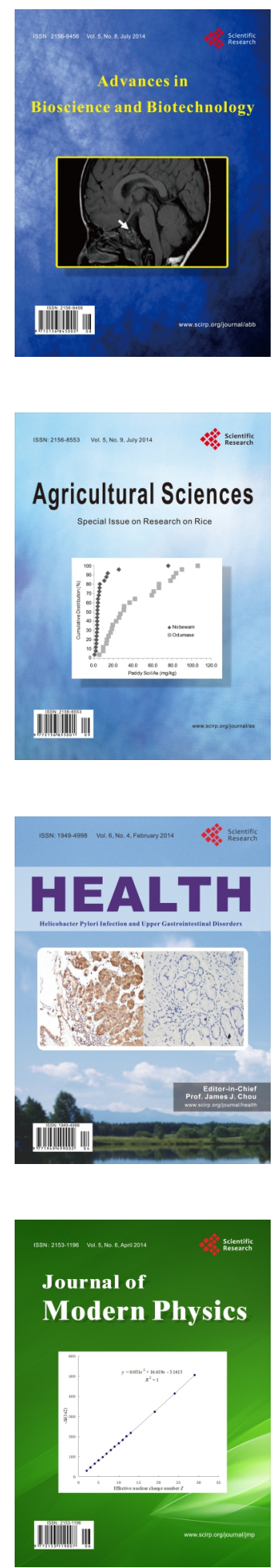
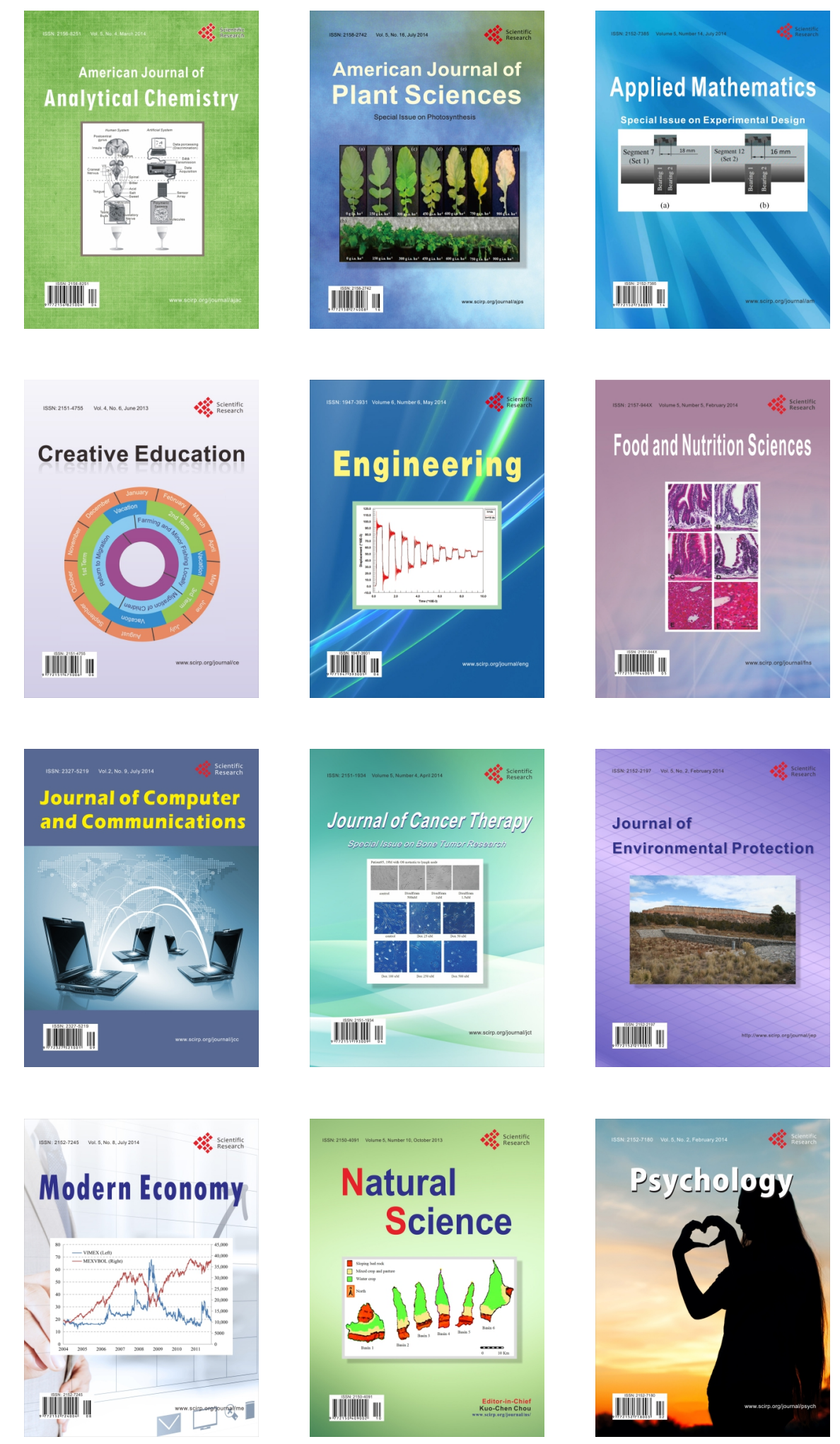